\title{
The Relationship Between Instructor Feedback and ESL Student Anxiety
}

\author{
Sabrina Di Loreto and Kim McDonough
}

This correlational study, conducted in intermediate English as a second language (ESL) high school classes in Quebec, investigated the relationship between instructor feedback and student anxiety. The participants were 53 ESL students in their last year of secondary school who were required to take an integrativewriting exam as part of their graduation requirements. Throughout a 5-month period, students took 2 practice integrative-writing tests, received written corrective feedback, and completed 5 questionnaires about their language learning anxiety, L2 writing anxiety, and perceptions about instructor feedback. The results showed a significant negative correlation between students' perceptions of feedback and test anxiety. The findings indicated that students with more positive perceptions of instructor feedback had lower anxiety.

Cette étude corrélationnelle, qui a eu lieu dans des classes d'ALS au secondaire au Québec, a porté sur le rapport entre la rétroaction de la part de l'enseignant et l'anxiété chez les élèves. Les participants, 53 élèves d'ALS en secondaire 5, devaient passer un examen de synthèse portant sur la rédaction de sorte à répondre aux exigences d'obtention de leur diplôme. Au cours d'une période de 5 mois, les élèves ont écrit 2 examens de synthèse de pratique, ont reçu de la rétroaction corrective par écrit et ont complété cinq questionnaires portant, d'une part, sur leur anxiété face à l'apprentissage d'une langue et la rédaction en $L 2$ et, d'autre part, sur leurs perceptions de la rétroaction par l'enseignant. Les résultats indiquent que les élèves ayant des perceptions plus positives de la rétroaction de l'enseignant souffraient moins d'anxiété.

A recent tendency in assessing English for academic purposes is to integrate reading and listening with writing (Weigle \& Parker, 2012). This type of assessment, called integrative writing, requires that the examinee read texts and/or listen to audio to obtain information that is used for a writing task. Integrated-writing tasks are increasingly used in many influential largescale assessment programs such as the Test of English as a Foreign Language (TOEFL), the International English Language Testing System (IELTS), and the Canadian Academic English Language (CAEL) test. Most integrative-writing tasks require discourse synthesis (Plakans, 2009a; Spivey \& King, 1989), in which students synthesize the content of written or aural texts by selecting relevant source information and incorporating it into their own ideas. Their written texts make connections between their ideas and the information from the sources to fulfill a specific purpose and respect an intended audience. 
According to Weigle (2004), one of the main reasons for using integrativewriting tasks is to enhance the authenticity of tests by basing the written task on actual source materials. By providing content for students to write about, integrative-writing tasks can essentially reduce content bias and avoid drawing on memory (Weigle, 2002). Another rationale for using integrativewriting tasks is for learners to demonstrate reading ability through writing, thereby showing language proficiency in different skill areas (Weigle, Yang, \& Montee, 2013).

However, integrative-writing tests also come with a number of challenges. According to Weigle and Parker (2012), there has been a great deal of discussion about whether test takers have the ability to incorporate source text materials appropriately. Providing texts may lead to inappropriate, misleading, or irrelevant textual borrowing if students are not aware of the cultural norms governing textual appropriation or lack the language skills necessary to paraphrase source texts within the time limits of a test situation (Cumming, 2013; Mateos \& Solé, 2009; Weigle, 2002). At the same time, students need to have reached a certain level of proficiency in a second language to perform the writing task because, without sufficient comprehension of the source materials, learners cannot write adequately about them (Cumming, 2013). Topic familiarity, reading comprehension skills, L2 proficiency, L1 reading and writing ability, and the complexity of the source texts also contribute to the difficulty of integrated-writing tests (Plakans, 2009a, 2009b; Spivey \& King, 1989; Wiley \& Voss, 1999). Finally, another challenge worth noting is students' understanding of the writing task (Wolfersberger, 2013). As well as the relevant writing skills and content knowledge, students also need to understand the task requirements and apply their skills and knowledge in ways that successfully accomplish those tasks.

Given that integrative writing is a highly complex task and is used for influential high-stakes tests, it may make students experience both general language learning anxiety and writing anxiety. According to Kimura (2008), anxiety has established itself as one of the most important affective factors responsible for individual differences in the success or failure of L2 learning, and it has become a widely investigated individual difference in the field of L2 acquisition (Baralt \& Gurzynski-Weiss, 2011). Anxiety is a complex, multidimensional phenomenon (MacIntyre \& Gardner, 1994), but the current consensus is that language anxiety should be viewed as a situation-specific construct that recurs consistently over time within the given context of language learning situations (Horwitz, 2001; Horwitz, Horwitz, \& Cope, 1986; MacIntyre \& Gardner, 1991). More specifically, foreign language anxiety is a distinct type of situation-specific anxiety that is particular to language learning and independent of other types of anxiety (Horwitz et al., 1986).

To measure foreign language anxiety, the Foreign Language Classroom Anxiety Scale (FLCAS) was created to assess learners' three sources of anxiety in foreign language learning: communication apprehension, test anxiety, and 
fear of negative evaluation (Horwitz et al., 1986). The FLCAS has been shown to have high reliability and is widely used as a measure of foreign language anxiety. However, because the majority of the FLCAS items measure anxiety in speaking a foreign language, researchers have questioned its adequacy for measuring anxiety about other skills (Cheng, 2004). Writing can also provoke anxiety amongst students, and research on the relationship between writing anxiety and personality characteristics has provided justification for regarding writing apprehension as a distinct form of anxiety. Writing anxiety refers to a situation-specific individual difference that reflects a person's inclination to approach or avoid situations that require writing, along with their perceptions of evaluation (Daly \& Miller, 1975b).

In order to measure writing anxiety, Daly and Miller (1975a) developed a standardized Likert-type writing anxiety questionnaire called the Writing Apprehension Test (WAT) related to three aspects of writing: tendencies to avoid writing, attitudes toward written communication, and feelings experienced during writing. Cheng (2004) adapted the WAT for use specifically with L2 writers, and his Second Language Writing Anxiety Inventory measures three dimensions of anxiety: physiological, behavioural, and cognitive responses. Physiological responses refer to unpleasant physical feelings such as nervousness and tension. Behavioural responses include avoidance behaviour, which includes various efforts to abstain from and avoid writing. Cognitive responses relate to cognitive anxiety and refer to the mental feature of the experience such as negative expectations, fixation on performance, and apprehension about others' perceptions. When writing tasks are used for high-stakes tests, L2 writers may also experience test anxiety that manifests through physical reactions (sweating, racing heart rate) and behavioural responses (fidgeting, pencil tapping) (Cizek \& Burg, 2006). In addition to triggering fear of negative evaluation, tests may also lead to anxiety because of their time constraints (Galassi, Frierson, \& Siegel, 1984), the testing situation (emotional atmosphere, presence of examiner, examiner-student rapport, clarity of instructions), and the test itself (e.g., perceived fairness, comprehensibility of items, interest in test content) (Zeidner \& Bensoussan, 1988).

In light of the anxiety that may occur when L2 writers are asked to perform complex integrated-writing tasks in high-stakes testing environments, an important question for instructors is how to help students prepare for these types of examinations. One way to help decrease students' anxiety is to administer practice tests so they can simulate a high-stakes test beforehand. In addition, providing students with feedback on their practice test performance may help reduce anxiety about their writing abilities and facilitate exam preparation. Although there has been a debate concerning the effectiveness of written corrective feedback (see Bitchener \& Ferris, 2012; Ferris, 1999, 2011; Hyland \& Hyland, 2006; Truscott, 1996, 2004, 2009), several studies have shown that written feedback helps students pay attention to language and can be incorporated into their subsequent writing tasks (Ashwell, 2000; 
Chandler, 2003; Ferris, 2006; Ferris \& Roberts, 2001). Studies have also shown that students react positively to feedback that focuses on all aspect of writing (for review of individual studies, see Bitchener \& Ferris, 2012) and that students appreciate teacher feedback (Leki, 1991; Zhang, 1995). They prefer to receive comprehensive feedback focusing on almost all errors, whether local (i.e., spelling, grammar, and punctuation) or global (i.e., ideas, content, and organization), fearing that any unmarked errors will affect them in the future (Bitchener \& Ferris, 2012; Lee, 2005; Leki, 1991). Although direct feedback requires less effort on the part of students, overall they prefer to receive indirect feedback, which allows them to be more active in their learning and helps improve their writing (Bitchener \& Ferris, 2012; Hyland \& Hyland, 2006). Finally, it is important to note that most research on students' perceptions about feedback has been carried out in college or university settings. There is much less research focusing on the secondary school context where students are often taught L2 writing explicitly and begin to develop attitudes toward L2 writing (see Lee, 2008).

However, it is possible that instructor feedback could make students feel demotivated or anxious about their writing (Krashen, 1984; Truscott, 1996; Zamel, 1985), although there is not much evidence about the nature of the specific relationship between instructor feedback and student anxiety. In Lee's (2008) study, students had difficulty acting on the teacher feedback, and this could have been due to language proficiency (ability to correct their errors) as well as motivation. Motivation in this study was linked with the teacher's personality and pedagogy where the teacher did not think highly of the students. As the students were not receiving positive encouragement from the teacher, the students lacked motivation. It is important to remember, however, that research has found motivation to be a main factor in second or foreign language achievement (Dörnyei, 2009). With low motivation, students might not take teacher feedback seriously (see Guenette, 2007). For example, Hyland (1998) reported that two ESL writers became less positive about their writing during a course in which they received feedback. His findings suggest that there needs to be a more open teacher/student dialogue on feedback, because it can lead to miscommunication and decrease student motivation.

To summarize, when integrative writing is used as a high-stakes assessment, students may experience anxiety. Considering the fact that L2 writing in general is demanding and anxiety-creating (Gupta, 1998), particularly in testing situations, research is needed in order to determine whether instructors can help reduce students' anxiety levels by administering practice integrative-writing tests and providing them with written corrective feedback. Practice exams with instructor feedback may help students have a better idea of what they need to do in order to improve, thereby decreasing their anxiety. And given that students have expressed appreciation for written corrective feedback, they may experience reduced anxiety about the high-stakes integrated-writing exam if they are given feedback on similar writing tasks. 
Accordingly, the purpose of this study was to explore the possible relationship between instructor feedback and students' anxiety. The research questions were as follows:

1. Do the foreign language learning anxiety and writing anxiety of ESL students change over time in an instructional setting?

2. What are the ESL students' perceptions about the instructor feedback they receive on practice integrative-writing exams?

3. Is there a relationship between the ESL students' perceptions of feedback and their anxiety about a high-stakes integrative-writing exam?

\section{Method}

\section{Participants and Context}

The participants were 53 high school students ( 22 boys, 31 girls) enrolled in ESL classes taught by the first researcher. They ranged in age from 16 to 17 years old and were in their final year of secondary school at a private French school near Montreal, Canada. The students were French Canadians who spoke French as their primary home and community language. Based on the English entrance exam taken upon entering secondary school, the students' proficiency was at the intermediate level. At the time the study was carried out, they had received roughly 540 hours of secondary school instruction in English that was designed to promote the three English competencies in the Quebec curriculum: interacts orally in English, reinvests understanding of texts, and writes and produces texts. At the end of the school year, the students had to pass an integrated-writing exam that assessed the latter two competencies. The exam was administered by the Ministère de l'Éducation, du Loisir et du Sport (MELS), and performance on the exam was crucial in determining whether students graduated from high school. The English credits from their English class were needed in order to receive the secondary school diploma, and it would have been difficult to obtain the necessary English credits without passing the integrated-writing exam.

\section{Integrated-Writing Exam}

The integrated-writing exam required that students write a 400-word, issuesand-trends feature article that took a critical look at a topic in order to help the reader better understand the issue. One week before the exam, the students were given a preparation booklet that contained texts about the topic. Throughout the week, they were asked to read, analyze, and synthesize their understanding of the texts with the help of a guiding question provided in the booklet. The day before the exam, they listened to a 10-minute audio recording about the topic followed by small group discussions about the written and aural texts. On the day of the exam, the students were given a prompt that narrowed the scope of the topic and indicated the perspective 
from which they should approach the topic. They were given three hours to write the exam, and they were allowed to use their preparation booklet. The topic of the integrated-writing exam was counterfeiting, and the prompt was to examine who was hurt by the counterfeit goods industry.

In terms of evaluation, two separate scores were given for the integrated-writing exam. The first score, worth 100 points, was based on the content of the exam and assessed the competency reinvests understanding of texts. Students had to select relevant information from the source texts (audio and print) and shape and develop ideas into an original, coherent, information-based feature article that provided the target audience with an in-depth look at the topic from the prescribed prompt. Elements such as how accurate the content was and whether the content was too general, repetitive, misleading, contradictory, unevenly shaped, or copied from source texts were considered when awarding points. The second score, worth 100 points, was divided between organization (30 points) and language (70 points) and assessed the competency writes and produces texts. For organization, the feature article had to contain a catchy and engaging introduction, a clear purpose, and informative content that was logically organized with appropriate paragraphing and transitions. To reflect the genre, the organization of the feature article had to present a headline and secondary headline, a lead that hooked the reader, and a closing that emphasized the writer's perspective. Additional criteria assessed as part of organization included the use of two quotations to show credibility or provide eyewitness accounts along with an image that presented a caption, a sidebar, or a pullquote. For language, the feature article had to have the appropriate voice and tenses, vocabulary, and grammatical structures that promoted comprehension. The text also needed to be engaging, as evidenced by appropriate idiomatic language, with varied sentence structures and rhetorical devices that respected the tone of a feature article.

\section{Materials}

Practice exams. In order to help the students prepare for the integrated-writing exam, two practice exams were administered by the first researcher. Both practice exams were created by the MELS and had been used in previous exam administrations. The topic of the first practice exam was Underwater Shipwrecks. Approximately half the students were told to write a feature article about the debate over the ownership of artifacts recovered from shipwrecks, while the other half were asked to examine the debate between archaeologists and treasure hunters regarding underwater shipwrecks. Both prompts were created by the MELS and were included in the practice exam materials. The second practice exam was on the topic of Space Exploration, and the only prompt provided by the MELS was to examine the main challenges of future space exploration.

Anxiety questionnaires. Three questionnaires were used to assess the students' general language learning anxiety, elicit their perceptions about the 
instructor's written feedback, and report their anxiety about the integratedwriting exam. All questionnaires were written in English. The first questionnaire was the language learning anxiety inventory, which measured both foreign language anxiety generally and L2 writing anxiety specifically (see Appendix A). Fifty-five items were compiled from the FLCAS (Horwitz et al., 1986) and SLWAI (Cheng, 2004). Each item included a 5-point Likert scale ranging from strongly disagree to strongly agree. The 32 items modified from FLCAS contained statements in three domains: 11 items for communication apprehension (Cronbach's $\alpha=.83$ ), 15 items for test-anxiety ( $\alpha=.85$ ), and 6 items for fear of negative evaluation $(\alpha=.82)$. The 23 items from SLWAI (Cheng, 2004) contained items related to three dimensions of writing anxiety: 9 items for cognitive responses $(\alpha=.82), 7$ items for physiological responses $(\alpha=.87)$, and 7 items for behavioural responses (.52). Due to low response consistency and the inapplicability of the behavioural responses items, they were removed from the subsequent analysis. Because the students were in an instructional context, it was not possible for them to avoid writing in English, and in their daily lives outside the classroom they likely had little need to write in English.

The second questionnaire (Appendix B) was created by the first researcher to measure the students' perceptions of the instructor's feedback in terms of their apprehension of the feedback (10 items), the usefulness of feedback (6 items), and the quality of feedback (8 items), using a 5-point Likert scale ranging from strongly disagree to strongly agree. The instructor feedback questionnaire was piloted with the first researcher's colleagues and former students and revised to promote readability and transparency based on their feedback. The internal response consistency (Cronbach's $\alpha$ ) was .84 for apprehension of feedback, .75 for usefulness of feedback, and .84 for quality of feedback.

The third questionnaire was created by the first researcher to measure student anxiety about the integrated-writing exam and whether the practice examinations and instructor feedback affected their exam anxiety (Appendix C). The items were organized into two categories: test anxiety (11 items) and perception of feedback ( 7 items) with a 5-point Likert scale ranging from strongly disagree to strongly agree. It also contained 9 open-ended questions to gain more insight into the students' (a) anxiety before and while writing the test, (b) perceptions about the feedback they had received, (c) suggestions about how the teacher can help reduce students' anxiety, (d) which feedback they preferred, and (e) how the feedback affected their confidence level. The questionnaire was pilot tested with the first researcher's colleagues and former students and revised based on their feedback. The internal response consistency (Cronbach's $\alpha$ ) was .88 for test anxiety and .73 for perceptions about feedback.

\section{Instructor Feedback}

The students wrote two practice exams, and for each they received written feedback from the instructor in three categories: content, organization, and language. Content feedback was written explicitly next to the paragraphs to 
indicate issues with the accuracy of the information, problems with copying from sources, a lack of focus, or a need for further explanation or clarification. Organization feedback was written explicitly next to the headline, secondary headline, lead, closing, or text components to specify whether it enhanced the article. If the content was well developed and the organization was appropriate, a checkmark was written next to the paragraph. Language feedback was given in the form of unfocused, indirect feedback by either coding or circling an error. Errors that were circled were common mistakes that had been discussed and reviewed previously in class. More complex errors or errors involving forms that had not been discussed previously were coded using a list that the students had received at the beginning of school year and used regularly throughout the year. Examples of the different kinds of instructor feedback are provided in Appendix D.

\section{Design and Procedure}

The current study employed a correlational design to identify the relationship between instructor feedback and English L2 students' anxiety. It was carried out over a five-month period, beginning in the middle of the school year (January) and ending in the middle of June after the students took the MELS integrated-writing exam. Before the study began, the students had already spent class time reviewing the content and organization of the integrated-writing exam. All research tasks were administered following the regular classroom schedule. When the students were not preparing for the exams, the regular curriculum was implemented. Because the first researcher was the students' instructor, the questionnaires were administered by her colleague, who retained the questionnaires until the students had graduated.

The students completed the language learning anxiety inventory in January before taking the first practice exam (about shipwrecks), also in January. After receiving instructor feedback about that practice exam, the students had time to review the comments and then completed the instructor feedback and anxiety questionnaire in February. In April, the students completed the second practice exam (about space exploration), received instructor feedback, and completed the instructor feedback and anxiety questionnaire for a second time. Three weeks later, at the end of May, the students took the MELS integratedwriting exam and completed the integrated-writing exam questionnaire in the following class period. Finally, the students completed the language learning anxiety inventory at the end of the school year in June to determine whether their general language anxiety and L2 writing anxiety level had changed.

\section{Data Scoring}

For all questionnaire items using 5-point Likert scales, each level on the scale was awarded from 1 to 5 points. For all positively worded statements, points were awarded ranging from 1 (strongly agree) to 5 (strongly disagree). For all 
negatively worded statements, the scoring was reversed (i.e., strongly agree $=5$ points). For the language learning anxiety inventory, high scores represented high levels of language learning anxiety and writing anxiety. For the instructor feedback questionnaire, high scores on the items in the category apprehension of feedback represented high levels of anxiety associated with instructor feedback, while high scores on the items in the categories usefulness of feedback and quality of feedback indicated positive perceptions about instructor feedback. For the integrative-writing exam questionnaire, high scores on the items about test anxiety indicated high levels of anxiety associated with the exam, while high scores on the perception of feedback items indicated positive perceptions about the instructor feedback. The open-ended questions on the integrative-writing exam questionnaire were analyzed by extracting responses and considering synonyms as answers for each question, then compiling frequency counts for each response type. The alpha-level for all statistical tests was set at .05 .

\section{Results}

The first research question asked whether the foreign language learning and writing anxiety of the ESL students changed over time in an instructional setting. As shown in Table 1, the students' scores on the general language learning anxiety inventory showed little change from January to June, and separate paired-samples $t$-tests for each anxiety category confirmed that there were no significant differences in their anxiety levels. The effect sizes (Cohen's $d$ ) did not reach the level traditionally referred to in applied linguistics research as "small."

Table 1

Comparison and Data for Language Learning Anxiety Inventory

\begin{tabular}{|c|c|c|c|c|c|c|c|c|c|}
\hline \multirow{2}{*}{$\begin{array}{l}\text { Categories of } \\
\text { anxiety }\end{array}$} & \multirow{2}{*}{$\begin{array}{l}\text { Mini- } \\
\text { mum } \\
\text { score }\end{array}$} & \multirow{2}{*}{$\begin{array}{l}\text { Maxi- } \\
\text { mum } \\
\text { score }\end{array}$} & \multicolumn{2}{|c|}{ January } & \multicolumn{2}{|c|}{ June } & \multicolumn{3}{|c|}{ Statistical comparison } \\
\hline & & & $M$ & $S D$ & $M$ & $S D$ & $t$ & $p$ & $d$ \\
\hline $\begin{array}{l}\text { Communication } \\
\text { apprehension }\end{array}$ & 11 & 55 & 26.58 & 6.91 & 25.36 & 6.16 & 1.79 & .08 & .19 \\
\hline Test-anxiety & 15 & 75 & 36.75 & 9.36 & 35.34 & 9.95 & 1.79 & .08 & .15 \\
\hline $\begin{array}{l}\text { Fear of negative } \\
\text { evaluation }\end{array}$ & 7 & 35 & 15.58 & 4.66 & 15.19 & 4.77 & 0.80 & .43 & .08 \\
\hline $\begin{array}{l}\text { Cognitive } \\
\text { anxiety }\end{array}$ & 9 & 45 & 24.25 & 6.44 & 23.79 & 5.87 & 0.69 & .50 & .07 \\
\hline Somatic anxiety & 7 & 35 & 15.49 & 5.57 & 14.49 & 5.18 & 1.84 & .07 & .19 \\
\hline
\end{tabular}

The second research question asked how students perceived the written corrective feedback they received on their practice integrated-writing exams. As shown in Table 2, the students' perceptions about the usefulness of feedback and the quality of feedback showed no change from the first practice test to the second practice test, and the effect sizes were minimal. However, their 
scores for apprehension of feedback decreased significantly from the first practice exam to the second practice exam, and there was a large effect size.

Table 2

Comparison and Data for Instructor Feedback Anxiety Questionnaire

\begin{tabular}{|c|c|c|c|c|c|c|c|c|c|}
\hline \multirow{2}{*}{$\begin{array}{l}\text { Categories of } \\
\text { feedback }\end{array}$} & \multirow{2}{*}{$\begin{array}{l}\text { Mini- } \\
\text { mum } \\
\text { score }\end{array}$} & \multirow{2}{*}{$\begin{array}{l}\text { Maxi- } \\
\text { mum } \\
\text { score }\end{array}$} & \multicolumn{2}{|c|}{$\begin{array}{c}\text { After } \\
\text { practice \#1 }\end{array}$} & \multicolumn{2}{|c|}{$\begin{array}{c}\text { After } \\
\text { practice \#2 }\end{array}$} & \multicolumn{3}{|c|}{ Statistical comparisor } \\
\hline & & & $M$ & $S D$ & $M$ & $S D$ & $t$ & $p$ & $d$ \\
\hline $\begin{array}{l}\text { Apprehension of } \\
\text { feedback }\end{array}$ & 10 & 50 & 27.06 & .90 & 23.55 & .76 & 4.92 & .01 & 4.23 \\
\hline $\begin{array}{l}\text { Usefulness of } \\
\text { feedback }\end{array}$ & 6 & 30 & 19.06 & 4.96 & 18.32 & 5.20 & 1.32 & .19 & .15 \\
\hline $\begin{array}{l}\text { Quality of feed- } \\
\text { back }\end{array}$ & 8 & 40 & 12.13 & 3.34 & 12.06 & 3.78 & 0.16 & .87 & .02 \\
\hline
\end{tabular}

The students' responses to the open-ended questions on the integratedwriting exam questionnaire also provided insight into their perceptions about instructor feedback. When asked which types of feedback they liked receiving, 33 students stated that they preferred content feedback because of its high value for their exam score. They also stated that content comments let them know whether they had understood the readings, which made them feel better as writers. Fourteen students preferred feedback on organization, and only six students said they liked coded language feedback, while none of them mentioned uncoded language feedback.

When asked which type of feedback made them feel more confident about their writing, 28 out of 52 student responses were about organization feedback. The general reasons were that it was something they had to learn and follow, and it was something they had control over: "Organization because for all the texts we get to write, it is always the same so I felt prepared for this." Some even stated that it is something they always do well on: "The feedback on organization was mostly excellent and so it made me feel a lot more confident." Thirteen students said that content feedback helped them realize that they had understood the task and were on the right track: "Feedback about content because it made me realize that I'm not so far from a good grade after all." Other aspects of feedback that students highlighted as giving them confidence included language feedback because it is something they do well, and any kind of positive feedback. Interestingly, three students stated that a lack of comments made them confident in general because it meant that they were doing well and had not made an error.

When the students were asked which type of feedback made the participants feel nervous about their writing, their 51 responses were content (17), organization (10), language with codes (8), language without codes (5), content and organization (1), grammar in general (1), negative feedback in general (1), and none of the feedback types (8). Feedback on content was 
selected the most because it was something they struggled with and wanted to do well but did not understand how to improve. Organization feedback made some students nervous because they believed that their organization of the texts was correct, but the feedback made them realize that they had not understood the task requirements. However, some students pointed out that none of the feedback affected their anxiety. For example one student wrote that "none made me nervous. It just helps me improve!"

The third research question asked whether there was a relationship between students' perceptions of feedback and their test anxiety. On the integrated-writing exam questionnaire, their mean score for the perception of feedback was 20.74 (out of 25) while their mean score for test anxiety was 29.30 (out of 50). The Pearson's product-moment correlation showed a significant, moderate negative correlation between the scores: $r(53)=-.52, p=$ .001 , which is illustrated in Figure 1. As evidenced by the absolute value of $r$ (.52) the effect size reached the level typically considered "large" in applied linguistics research.

We look next at the open-ended questions on the integrated-writing exam questionnaire. When asked to describe how they felt before writing the highstakes exam, 26 of the 52 students who replied said that they were nervous for various reasons. The most common reasons for anxiety included not knowing the exam topic and feeling pressure due to the high-stakes nature of the exam. Despite being nervous, 25 students stated that they were confident: 17 of them because they felt prepared and 3 because the feedback on their practice exams had helped them. One student stated that he did not want to write the exam due to lack of sleep, but made no reference to confidence or stress. When asked specifically whether instructor feedback helped them write the exam, 26 students stated that the feedback reduced their stress and made them feel more confident, and 22 students reported that it helped them understand how to improve and encouraged them to do better. Only 3 students indicated that the feedback made them more stressed. Overall, the students' comments suggest that the instructor feedback helped reduce their test anxiety.

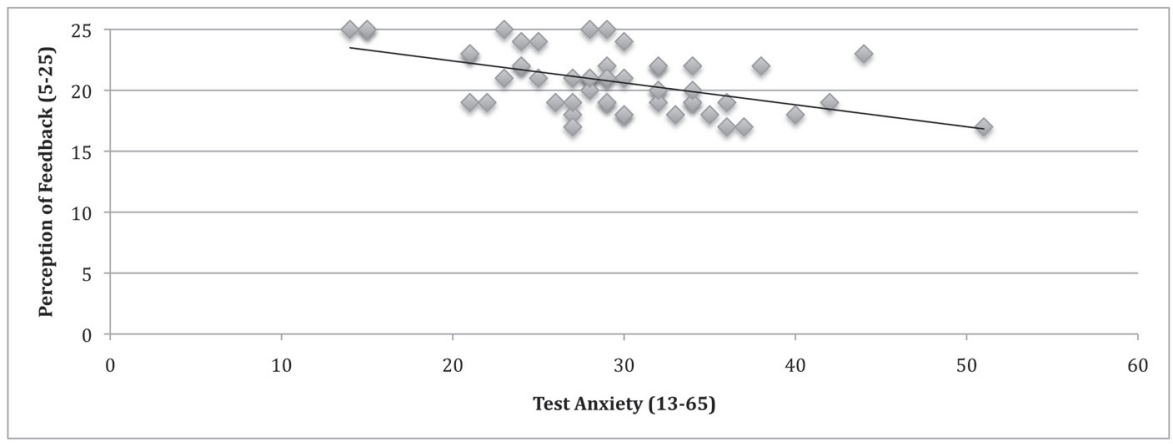

Figure 1. Relationship between test anxiety and perception of feedback. 


\section{Discussion}

The primary objective of this study was to explore the relationship between instructor feedback and ESL students' anxiety. In analyzing the first research question concerning foreign language learning and writing anxiety, it came as no surprise that the students' scores showed little change from January to June. This finding confirms previous research that language learning anxiety should be considered as a situation-specific construct that recurs habitually over time in language learning situations (Horwitz, 2001; Horwitz et al., 1986; MacIntyre \& Gardner, 1991). Given that there was a high-stakes integrativewriting exam at the end of the year, this could help explain why test anxiety did not decrease as the students were aware that successful performance on the exam was crucial to graduate from secondary school.

For the second research question, the students' perceptions about the instructor feedback showed little change in terms of the quality and usefulness of feedback, but their apprehension of instructor feedback decreased after the second practice exam. Previous research has shown that students are eager to have all their errors pointed out to them, whether they are local (i.e., spelling, grammar, and punctuation) or global (i.e., ideas, content, and organization) (Bitchener \& Ferris, 2012; Lee, 2005; Leki, 1991). The students' open-ended responses showed that they appreciated feedback on an aspect of the integrated-writing exam that was highly valued in the evaluation criteria-content (100 points). Interestingly, although language was worth more points than organization (70 and 30, respectively), students expressed more positive comments about organization feedback than language feedback. One possible explanation is that they perceived organization as something that they could be taught explicitly and improve through practice, and that doing so could give them a high or perfect score. In contrast, students may have expressed more negative comments about language feedback because they did not believe that it was possible to obtain perfect scores or that practice could improve their language use. An alternative explanation is that the students may have made few positive comments about language feedback (whether coded or not coded) because they did not understand the codes or how to correct their errors. As pointed out by Lee (2008), students may have difficulty understanding feedback at times, which would help explain why there was no change in the students' perceptions about the usefulness or quality of feedback from the first practice test to the second.

In addition to showing no increase in their perceptions about the quality and usefulness of feedback, the students' ratings for these items remained low after both practice exams. One possibility is that the students did not regard written corrective feedback as being useful, as has been suggested by Truscott $(1996,2004,2009)$. However, 26 students stated that the feedback made them feel more confident and actually reduced their stress about writing the final exam. Furthermore, 22 students stated that the feedback either 
helped them want to improve for the next task or gave them confirmation that they were on the right track. In looking at the open-ended questions, the students were more confident with the sections they could control, such as the organization of the integrative task, because it was something they could study and master with practice. However, given the variation in answers as to which type of feedback made the students more or less confident about their writing ability, it is difficult to determine conclusively which types of feedback positively or negatively affect each individual student. As Ferris (2011) has pointed out, the issues of student preferences and individual differences have not received much attention in the writing feedback literature.

The results of an analysis of the third research question (whether there was a relationship between students' perceptions of feedback and their test anxiety) showed a significant, negative correlation between the two categories, which means that positive perceptions of feedback were associated with lower test anxiety. The majority of the students (50 of 53) stated that they felt more confident or felt encouraged to do better when they received feedback, with only 3 students reporting that feedback contributed to their stress. Finally, it is important to note that the students had mentioned that the topic chosen for the integrative-writing exam (counterfeiting) was more interesting than the practice exams (underwater shipwrecks and space exploration). This could have had an effect on their anxiety during the test and led them to have positive feelings about the exam when they filled out the final questionnaire.

The students' responses to the open-ended questions raised a number of issues with potential pedagogical implications. First, students may need positive encouragement and feedback. As much as instructors try to help students by providing a great deal of constructive comments, positive and encouraging feedback can help prevent students from becoming demotivated or anxious about their writing. If students react to a low score with frustration and disappointment, positive feedback can play an important role in helping them persist in their efforts to improve. Second, in light of the students' comments that they did not understand language feedback, whether with or without codes, more instructor assistance may be needed for them to be able to benefit from feedback (see Ferris, 2011, for a comprehensive list of considerations in giving feedback). For example, a graph could also be given to the students before they receive their evaluation, explaining how to read the feedback so that they know how it pertains to the evaluation criteria (for example, whether the feedback is for content, organization, or language). That way, they will know which area of the writing task they need to improve.

Finally, because integrative-writing tasks are becoming more widely used for assessing academic writing, instructors may need to make sure they teach students how to incorporate source text materials appropriately by using paraphrasing strategies, especially in settings where students are more accustomed to independent-writing tests. The first researcher, who was also the instructor, noticed that the students had difficulty on the practice exams 
when appropriating source text information. Extensive exercises on paraphrasing may be needed before administering integrative-writing tests so that students acquire the strategies needed for a discourse synthesis task. At the same time, the integrative-writing task requirements need to be made explicit to students. As Wolfersberger (2013) has pointed out, teachers need to articulate and communicate the writing task to their students by reviewing materials before the test in order to understand what is required. If available, exemplars of the writing task could be modelled or given as examples, and the students could grade them using the evaluation criteria as a way to promote understanding of the task requirements.

As with most research, there are limitations. The participants were teenagers, and given that the first researcher was their instructor, they may have been influenced by this relationship when filling out the questionnaires even though they knew that she would not see the responses until after they graduated. Conversely, some students were upset about their grades for the practice exams and blamed the instructor, even though she had no control over the content, format, or evaluation criteria used by the government of Quebec. Because of the high-stakes nature of the integrated-writing exam, it was not possible to include a control group that did not receive practice exams or written feedback. The individual and combined impact of practice and feedback could be tested empirically through lab-based research. However, in the classroom context reported here, the primary goal was to maximize learning and test performance for all students by providing both practice and feedback. Because the study was carried out in a high-stakes exam preparation setting, more research is needed in contexts where the consequences of poor test performance are less severe. Finally, because correlation research focuses on the relationship between variables rather than cause-effect patterns, future studies might investigate how various combinations of student anxiety and written feedback impact students' writing development.

To conclude, because integrative writing is being used in large-scale assessment contexts, students may suffer from anxiety that negatively impacts their performance. However, providing practice exams and giving feedback for content, organization, and language may be one avenue for reducing student anxiety. Although the current study found that positive perceptions about feedback were associated with lower anxiety, it is important to take into consideration that feedback alone may not be enough to decrease anxiety. Both the teacher and each individual student have a role to play in the process of developing students' integrative-writing skills as well as working to reduce anxiety.

\section{Acknowledgements}

This manuscript reports the findings of the first author's MA thesis (Di Loreto, 2014): I am indebted to the administration of College Jean de la Mennais for granting me permission to carry out my thesis study and to my students for their participation in my research. Both authors would also like to thank the committee members - Sarita Kennedy and Joanna White-for their 
helpful advice and feedback on the thesis. Finally, we would like to thank the editor of TESL Canada Journal and the anonymous reviewers for their insightful comments and suggestions on an earlier version of this article. Some of the data were presented at the 2013 conference of Société pour le perfectionnement de l'enseignement de l'anglais langue seconde au Québec (SPEAQ) in Montreal, Quebec.

\section{The Authors}

Sabrina Di Loreto is a high school ESL teacher at College Jean de la Mennais in Montreal. She has an MA in Applied Linguistics from Concordia University. Her research interests include written corrective feedback and anxiety.

Kim McDonough is an associate professor and Canada Research Chair in Applied Linguistics at Concordia University. Her research interests include interaction and usage-based approaches to second language acquisition, structural priming, low-variability input, and task-based language teaching.

\section{References}

Ashwell, T. (2000). Patterns of teacher response to student writing in a multiple-draft composition classroom: Is content feedback followed by form feedback the best method? Journal of Second Language Writing, 9(3), 227-258.

Baralt, M., \& Gurzynski-Weiss, L. (2011). Comparing learners' state anxiety during task-based interaction in computer-mediated and face-to-face communication. Language Teaching Research, 15(2), 201-229.

Bitchener, J., \& Ferris, D. R. (2012). Written corrective feedback in second language acquisition and writing. New York, NY: Routledge.

Chandler, J. (2003). The efficacy of various kinds of error feedback for improvement in the accuracy and fluency of L2 student writing. Journal of Second Language Writing, 12(3), 267-296.

Cheng, Y.-S. (2004). A measure of second language writing anxiety: Scale development and preliminary validation. Journal of Second Language Writing, 13(4), 313-335.

Cizek, G. J., \& Burg, S. S. (2006). Addressing test anxiety in a high-stakes environment. Thousand Oaks, CA: Corwin Press.

Cumming, A. (2013). Assessing integrated writing tasks for academic purposes: Promises and perils. Language Assessment Quarterly, 10(1), 1-8.

Daly, J. A., \& Miller, M. D. (1975a). Apprehension of writing as a predictor of message intensity. Journal of Psychology, 89(2), 175-177.

Daly, J. A., \& Miller, M. D. (1975b). The empirical development of an instrument to measure writing apprehension. Research in the Teaching of English, 9(3), 242-249.

Di Loreto, S. (2014). The relationship between instructor feedback and foreign language anxiety (Unpublished master's thesis). Concordia University, Montreal, Quebec.

Dörnyei, Z. (2009). The psychology of second language acquisition. Oxford, UK: Oxford University Press.

Ferris, D. (1999). The case for grammar correction in L2 writing classes: A response to Truscott (1996). Journal of Second Language Writing, 8(1), 1-11.

Ferris, D. (2006). Does error feedback help student writers? New evidence on the short- and longterm effects of written error correction. In K. Hyland \& F. Hyland (Eds.), Feedback in second language writing: Contexts and issues (pp. 81-104). Cambridge, UK: Cambridge University Press.

Ferris, D. R. (2011). Treatment of error in second language student writing (2nd ed.). Ann Arbor, MI: University of Michigan Press.

Ferris, D., \& Roberts, B. (2001). Error feedback in L2 writing classes: How explicit does it need to be? Journal of Second Language Writing, 10(3), 161-184.

Galassi, J. P., Frierson, H. T., \& Siegel, R. G. (1984). Cognitions, test anxiety, and test performance: 
A closer look. Journal of Consulting and Clinical Psychology, 52(2), 319-320.

Guenette, D. (2007). Is feedback pedagogically correct? Research design issues in studies of feedback on writing. Journal of Second Language Writing, 16(1), 40-53.

Gupta, R. (1998). Writing with a different tool. In C. S. Ward \& W. A. Renandya (Eds.), Computers and language learning (pp. 97-120). Singapore: SEAMEO Regional Language Center.

Horwitz, E. (2001). Language anxiety and achievement. Annual Review of Applied Linguistics, 21, $112-126$.

Horwitz, E. K., Horwitz, M. B., \& Cope, J. (1986). Foreign language classroom anxiety. Modern Language Journal, 70(2), 125-132.

Hyland, F. (1998). The impact of teacher written feedback on individual writers. Journal of Second Language Writing, 7(3), 255-286.

Hyland, K., \& Hyland, F. (2006). Feedback on second language students' writing. Language Teaching, 39(2), 83-101.

Kimura, H. (2008). Foreign language listening anxiety: Its dimensionality and group differences. JALT Journal, 30(2), 173-196.

Krashen, S. D. (1984). Writing: Research, theory, and applications. Oxford, UK: Pergamon Institute of English.

Lee, I. (2005). Error correction in the L2 writing classroom: What do students think? TESL Canada Journal, 22(2), 1-16.

Lee, I. (2008). Student reactions to teacher feedback in two Hong Kong secondary classrooms. Journal of Second Language Writing, 17(3), 144-164.

Leki, I. (1991). The preferences of ESL students for error correction in college-level writing classes. Foreign Language Annals, 24(3), 203-218.

MacIntyre, P. D., \& Gardner, R. C. (1991). Methods and results in the study of anxiety and language learning: A review of the literature. Language Learning, 41(1), 85-117.

MacIntyre, P. D., \& Gardner, R. C. (1994). The subtle effects of language anxiety on cognitive processing in the second language. Language Learning, 44(2), 283-305.

Mateos, M., \& Solé, I. (2009). Synthesising information from various texts: A study of procedures and products at different educational levels. European Journal of Psychology of Education, 24(4), 435-451.

Plakans, L. (2009a). Discourse synthesis in integrated second language writing assessment. Language Testing, 26(4), 561-587.

Plakans, L. (2009b). The role of reading strategies in integrated L2 writing tasks. Journal of English for Academic Purposes, 8(4), 252-266.

Spivey, N. N., \& King, J. R. (1989). Readers as writers composing from sources. Reading Research Quarterly, 24(1), 7-26.

Truscott, J. (1996). The case against grammar correction in L2 writing classes. Language Learning, $46(2), 327-369$.

Truscott, J. (2004). Evidence and conjecture on the effects of correction: A response to Chandler. Journal of Second Language Writing, 13(4), 337-343.

Truscott, J. (2009). Arguments and appearances: A response to Chandler. Journal of Second Language Writing, 18(1), 59-60.

Weigle, S. C. (2002). Assessing writing. Cambridge, UK: Cambridge University Press.

Weigle, S. C. (2004). Integrating reading and writing in a competency test for non-native speakers of English. Assessing Writing, 9(1), 27-55.

Weigle, S. C., \& Parker, K. (2012). Source text borrowing in an integrated reading/writing assessment. Journal of Second Language Writing, 21(2), 118-133.

Weigle, S. C., Yang, W., \& Montee, M. (2013). Exploring reading processes in an academic reading test using short-answer questions. Language Assessment Quarterly, 10(1), $28-48$.

Wiley, J., \& Voss, J. F. (1999). Constructing arguments from multiple sources: Tasks that promote understanding and not just memory for text. Journal of Educational Psychology, 91(2), 301-311.

Wolfersberger, M. (2013). Refining the construct of classroom-based writing-from-readings assessment: The role of task representation. Language Assessment Quarterly, 10(1), 49-72.

Zamel, V. (1985). Responding to student writing. TESOL Quarterly, 19(1), 79-102. 
Zeidner, M., \& Bensoussan, M. (1988). College students' attitudes towards written versus oral tests of English as a foreign language. Language Testing, 5(1), 100-114.

Zhang, S. (1995). Reexamining the affective advantage of peer feedback in the ESL writing class. Journal of Second Language Writing, 4(3), 209-222.

\section{Appendix A}

\section{Language Learning Anxiety Inventory Items by Category}

\section{Communication Apprehension}

- I never feel quite sure of myself when I am speaking in my English class.

- I start to panic when I have to speak without preparation in English class.

- I get nervous when I don't understand every word the English teacher says.

- It frightens me when I don't understand what the teacher is saying in English.

- I am not nervous speaking English with native speakers.

- I feel confident when I speak in English class.

- I usually feel comfortable around native speakers of English.

- I feel overwhelmed by the number of rules you have to learn to speak English.

- I get upset when I don't understand what the teacher is correcting.

- I feel very self-conscious about speaking English in front of other students.

- I get nervous and confused when I am speaking in my English class.

\section{Test Anxiety}

- I am usually at ease during tests in my English class.

- I don't understand why some people get so upset over English classes.

- I worry about the consequences of failing my English class.

- The more I study for an English test, the more confused I get.

- I don't feel pressure to prepare very well for English class.

- English class moves so quickly I worry about getting left behind.

- When I'm on my way to English class, I feel very sure and relaxed.

- I get scared when I know that I'm going to be called on in English class.

- It wouldn't bother me at all to take more English classes.

- In English class, I can get so nervous I forget things I know.

- Even if I am well prepared for English class, I feel anxious about it.

- I often feel like not going to my English class.

- I can feel my heart pounding when I'm going to be called on in English class.

- I feel more tense and nervous in my English class than in my other classes.

- During English class, I find myself thinking about things that have nothing to do with the course. 


\section{Fear of Negative Evaluation}

- I am afraid that my English teacher is ready to correct every mistake I make.

- I keep thinking that the other students are better at languages than I am.

- I always feel that the other students speak English better than I do.

- It embarrasses me to volunteer answers in my English class.

- I don't worry about making mistakes in English class.

- I get nervous when the English teacher asks questions which I haven't prepared in advance.

Cognitive Anxiety

- I don't worry at all about what other people think of my English composition.

- I'm not afraid at all that my English compositions would be given a poor grade.

- I don't worry that my English compositions are a lot worse than others.

- I'm afraid that the other students would make fun of my English composition if they read it.

- I'm afraid of my English composition being chosen as a sample for discussion in class.

- While writing in English, I'm not nervous at all.

- If my English composition is to be evaluated, I would worry about getting a very poor grade.

- While writing English compositions, I feel worried and uneasy if I know they will be evaluated.

- I am afraid that my English teacher is ready to correct every mistake I make.

\section{Somatic Anxiety}

- My thoughts become mixed when I write English compositions under a time limit.

- My mind goes blank when I start to work on an English composition.

- I often feel panic when I write English compositions under a limited timeframe.

- I tremble or sweat when I write English compositions under time pressure.

- I feel my heart pounding when I write English compositions under a limited timeframe.

- I usually feel my whole body rigid and tense when I write English compositions.

- I freeze up when unexpectedly asked to write English compositions. 


\section{Avoidance Behaviour}

- I would do my best to excuse myself if asked to write English compositions.

- Whenever possible, I would use English to write compositions.

- I usually seek every possible chance to write English compositions outside of class.

- I often choose to write down my thoughts in English.

- I usually do my best to avoid writing English compositions.

- Unless I have no choice, I would not use English to write compositions.

- I do my best to avoid situations in which I have to write in English.

Note. Fifty-five items were compiled from the FLCAS (Horwitz, et al., 1986) and SLWAI (Cheng, 2004). Each item included a 5-point Likert scale ranging from strongly disagree to strongly agree.)

\section{Appendix B}

\section{Instructor Feedback Anxiety Questionnaire Items by Category}

Apprehension of Feedback

- The feedback made me nervous about my writing ability.

- The feedback did not make me stressed about my writing ability.

- I felt nervous when I saw that the teacher wrote comments in my feature article.

- Seeing comments from my teacher did not make me feel stressed.

- I enjoyed receiving feedback because I felt that the teacher was trying to help.

- I did not like the comments from the teacher because I felt the teacher was attacking my writing ability.

- The feedback received did not affect my attitude towards the writing task.

- I did not care that there was feedback given.

- Reading the comments from my teacher makes me more nervous to write the next time.

- Reading the feedback decreased my anxiety because I know how to improve.

\section{Usefulness of Feedback}

- I don't like getting feedback because I don't know how to improve.

- I like receiving feedback but I still don't know how to improve.

- I don't like receiving feedback because I don't want to know how to improve.

- I enjoy receiving feedback because I try to understand the comments so that I can do better the next time.

- I see no need to receive feedback because I rarely understand what the teacher means. 
- I do not know how to apply the feedback that I received.

\section{Quality of Feedback}

- The feedback was helpful.

- The comments were not useful.

- I did not understand any of the feedback received.

- I understood the feedback received.

- I found the feedback unclear.

- The feedback received did not confuse me.

- I don't need help from my teacher to understand the comments.

- I need support from my teacher to understand the comments received.

\section{Appendix C}

\section{Integrated-Writing Exam Questionnaire Items}

\section{Test Anxiety}

- I was tense and uneasy writing the test.

- I was not nervous writing the test.

- I felt unprepared writing this test.

- I felt ready writing this test.

- I think I was overreacting before writing this test.

- Although I was overreacting before the test, I had a reason to be nervous because it was difficult.

- The test was not so hard after all.

- We should have done more than two practice tests.

- Doing two practice tests was enough practice.

- My ideas and words came easy while writing this test.

- I had difficulty concentrating while writing this test.

- I did not know what to do during this test.

- I was confident while writing this test.

Perception of Feedback

- The feedback from the two practice tests helped me to write this test.

- The comments from the two practice tests from my teacher were useless since I still did not know how to write this test.

- I could not remember the feedback I received from the two practice tests.

- I remembered the feedback I received from the practice test but I did not know how to apply it.

- I remembered the feedback I received from the two practice tests and applied it to the best of my ability to write the MELS exam.

\section{Open-ended Questions}

- How did you feel before writing this test? Explain why you felt this way. 
- Did getting teacher feedback on your practice tests affect how you felt about this test? Explain your answer.

- Did getting teacher feedback on your practice tests affect the quality of your writing while taking this test?

- What do you think your teacher should have done to help reduce your anxiety or increase your confidence in writing the end-of-year exam?

- Which type of feedback did you prefer receiving? Rank them in order of preference.
(a) feedback on content
(b) feedback on form with codes (VT, S, SP, etc.)
(c) feedback on form that is not coded (underlined or circled)
(d) feedback on organization

- Of the feedback types (a) through (d), which one ...

... did you appreciate the most? Why?

... did you think was useless? Why?

... made you feel more confident about your writing? Why?

... made you feel nervous about your writing? Why?

\section{Appendix D}

\section{Instructor Feedback by Type}

1. Comments about organization

\begin{tabular}{|c|c|}
\hline Text Form & Comments \\
\hline \multirow[t]{2}{*}{ Headline } & subject? \\
\hline & simple \\
\hline \multirow[t]{2}{*}{ Secondary headline } & 1 sentence \\
\hline & angle? \\
\hline \multirow[t]{2}{*}{ Lead } & not catchy enough \\
\hline & angle? \\
\hline Body & subheadings will help \\
\hline \multirow[t]{2}{*}{ Closing } & not very effective \\
\hline & full circle? \\
\hline \multirow[t]{3}{*}{ Picture } & caption? \\
\hline & IN a paragraph \\
\hline & location? \\
\hline \multirow[t]{3}{*}{ Side-Bar } & IN a paragraph \\
\hline & location? \\
\hline & no use \\
\hline \multirow[t]{3}{*}{ Pull-Quote } & IN a paragraph \\
\hline & location? \\
\hline & not a catchy quote \\
\hline
\end{tabular}


2. Examples of language mistakes that were circled

\begin{tabular}{ll} 
Mistake & Example \\
\hline Verb tense conjugation & simple tenses, progressive tenses, past participle \\
Singular/plural nouns & spelling \\
Articles & a vs. an \\
Simple spelling mistakes & futur, wich \\
Names & M. John Smith \\
Capitalization & english, french \\
Punctuation & commas in parallel structure; joining two independent clauses \\
\hline
\end{tabular}

3. List of codes

S Spelling mistake

P Punctuation

What did he say_ What did he say?

C Capitalization

I am studying english. I am studying English

SP Singular-Plural: could be a singular/plural change

Two shoe Two shoes

WF Word form: right word but not in the right form

I saw a beauty picture. I saw a beautiful picture.

WC Word choice: change your word

She got on the taxi. She got into the taxi.

PO Possession: omit or add possession

It is Julie sweater. It is Julie's sweater.

$\wedge \quad$ Add word: missing a word

I want () go to the zoo. I want to go to the zoo.

WO Word order: right words, but not in the right order

I saw five times the movie. I saw the movie five times.

VT Verb tense: not in the right tense

I go to the store yesterday. I went to the store yesterday.

SV Subject-verb agreement

He eat sandwiches every day. He eats sandwiches every day.

IS Incomplete sentence

I went to bed. Because I was tired.

I went to bed because I was tired.

ROS Run-on sentence

My roommate was sleeping, I didn't want to wake her.

My roommate was sleeping. I didn't want to wake her.

AWK Awkward

Rephrase your sentence

R Repetitive/redundant

Fix your word/phrase/sentence 